\title{
Dunking behaviour in Carib grackles
}

\author{
JULIE MORAND-FERRON, LOUIS LEFEBVRE, SIMON M. READER, \\ DANIEL SOL \& SANDRA ELVIN \\ McGill University, Montréal
}

(Received 3 June 2003; initial acceptance 7 September 2003;

final acceptance 21 January 2004; published online 29 September 2004; MS. number: A9625R)

\begin{abstract}
Dunking behaviour, the dipping of food in water, has been anecdotally observed in more than 25 species of birds in the wild, but its function and ecology have not been systematically studied. In experiments conducted in the field and in captivity on Carib grackles, Quiscalus lugubris, in Barbados, we showed that: (1) dunking rate in the field was influenced by food type and that moistening dry food seems to be one of the major benefits of dunking; (2) most dunking observed in the field was performed by a minority of individuals, but the vast majority (86\%) of grackles tested in captivity were capable of dunking; (3) a higher density of conspecifics at a water source was associated with a lower dunking rate and an increased risk of kleptoparasitism when dunking; and (4) there were consistent individual differences in dunking and stealing frequency. We conclude that dunking is part of the normal behavioural repertoire of Carib grackles in Barbados, and that the low frequency of the behaviour in the field did not result from the inability of some individuals to perform the technique, but more likely from the balance of costs and benefits affecting its expression.
\end{abstract}

Observers of animal behaviour are occasionally struck by foraging techniques that appear to be unusual, innovative, opportunistic and/or cognitively sophisticated. When systematically collected, observations of this type have been useful in testing links between innovative cognition, neurobiology, ecology and evolution in birds and primates (Reader \& Laland 2002, 2003; Lefebvre et al. 2004). Dunking, the dipping of food in water before ingestion, is one technique that is mentioned in these observations. More than 25 birds species have been reported to dunk food in the wild (Table 1), often in contexts that suggest washing of soiled or toxic food, softening of hard or dry items, or smoothing the fur or feathers of difficult-to-swallow prey. However, no study has yet documented individual rates of dunking, nor addressed experimentally the function of the behaviour.

Correspondence and present address: J. Morand-Ferron, Department of Biology, McGill University, Avenue Docteur Penfield, Montréal, PQ H3A 1B1, Canada (email: julie.morand-ferron@mail.mcgill.ca). S. Reader is now at Utrecht University, Behavioural Biology, Padualaan 14, P.O. Box 80086, 3508 TB Utrecht, The Netherlands. D. Sol is now at the Centre for Ecological Research and Forestry Applications (CREAF), Universitat Autonoma de Barcelona, 08193 Bellaterra, Barcelona, Catalonia, Spain.
In many cases, dunking seems to be performed by only a few individuals within a species and some observers suggest that putatively complex cognitive processes like insight (Pitochelli 1985) and social learning (Wible 1975) underlie the rare appearance of the technique. In contrast, others suggest that dunking might be part of the normal repertoire of entire genera like Corvus (Goodwin 1986) and Quiscalus (Jackson 1985). If this is the case, the rarity of observed dunking could be due to costs and benefits that apply to particular individuals and conditions. This situation would then be comparable to infrequent, but species-typical behaviour like bait fishing in green-backed herons, Butorides striatus, or twig tool use in woodpecker finches, Cactospiza pallida. Higuchi (1988) and Tebbich et al. (2001) have shown that these techniques are more frequent in conditions where simpler foraging behaviours like passive waiting and foliage gleaning, respectively, are less efficient.

In the context of field and aviary experiments in Barbados, we witnessed dunking in a species in which the behaviour had not been previously reported, the Carib grackle, Q. lugubris. Carib grackles dunked food by walking with it to a water source, dropping it (often repeatedly) in the water, and retrieving it either to eat it immediately or to fly away with it. In captivity, three wild-caught grackles dunked fruit offered as part of a food neophobia test, and 
Table 1. Reports of dunking behaviour in free-ranging birds

\begin{tabular}{|c|c|c|c|}
\hline Species & Items dunked & Reported context & Source \\
\hline Agelaius phoenicus & Bread, crackers & - & Luchtemeyer 1969 \\
\hline \multirow[t]{2}{*}{ Ardea cinerea } & Large dead rat & 1 & Banks 1982 \\
\hline & Dead starling & 1 & Bowey 1997 \\
\hline Ardea herodias & Common gopher & 1 & Otnes 1977 \\
\hline Calidris alpine & Worms & 2 & del Hoyo et al. 1996 \\
\hline Calidris ferruginea & Worms & 2 & del Hoyo et al. 1996 \\
\hline Charadrius vociferous & Frogs & 2 & Schardien \& Jackson 1982 \\
\hline Corvus caurinus & Broken whelks & 2 & Zach 1979 \\
\hline Corvus corax & Carrion & - & Jones 1979 \\
\hline \multirow[t]{3}{*}{ Corvus corone } & Hard, dry bread & 1 & Jones 1979 \\
\hline & Hard crusts of bread, jammy pastry & 1,2 & Goodwin 1986 \\
\hline & Nuts & - & Brampton 1994 \\
\hline Corvus coronoides & Stale bread & 1 & Reid \& Reid 1996 \\
\hline Corvus mellori & Boiled potatoes & 1 & Edmonds 1991 \\
\hline Corvus mellori & Meat, bread, bones & 1 & McMillan 1992 \\
\hline Corvus mellori & Toasted bread & 1 & Slee 1992 \\
\hline Corvus orru & Bread, dead sparrow & - & Mackay 1997 \\
\hline Corvus splendens & Hard crusts of bread & 1 & Goodwin 1986 \\
\hline Euphagus cyanocephalus & Grasshoppers & 3 & Koenig 1985 \\
\hline Larus delawarensis & Cheese crackers & - & Stokes \& Stokes 1985 \\
\hline Leptoptilos cruminiferus & Dung beetles & 2 & Seibt \& Wickler 1978 \\
\hline Limosa lapponica & Lugworms & 2 & Vader 1979 \\
\hline Limosa limosa & - & 2 & del Hoyo et al. 1996 \\
\hline Passer domesticus & Hard, dry bread crusts & 1 & Purser 1959 \\
\hline Porzana tabuensis & Caterpillar & 2 & Johnson 1976 \\
\hline Quiscalus lugubris & Dry dog food, bread, maraschino cherries & 1 & This study \\
\hline \multirow[t]{2}{*}{ Quiscalus major } & Bread & 1 & Wible 1975 \\
\hline & Dry dog food & 1 & Jackson 1985 \\
\hline \multirow[t]{2}{*}{ Quiscalus mexicanus } & Dry dog food, bread, insects, table scraps & 1 & Pulich 1969 \\
\hline & Pecans, table scraps & 1 & Stokes \& Stokes 1985 \\
\hline Quiscalus niger & - & - & $\begin{array}{l}\text { A. S. Griffin, } \\
\text { personal communication }\end{array}$ \\
\hline \multirow[t]{8}{*}{ Quiscalus quiscula } & Bread, crackers & 1 & Bent 1958 \\
\hline & Dry bread & 1 & Rand 1967 \\
\hline & Bread & - & Luchtemeyer 1969 \\
\hline & Dry bread & - & Nimmo 1970 \\
\hline & Dry bread & 1 & Nicklas 1974 \\
\hline & Bread, mulberry, cricket, peanuts, fruits & 1,2 & Wible 1975 \\
\hline & Bread, dried pastry & 1 & Jackson 1985 \\
\hline & $\begin{array}{l}\text { Stale bread, } \\
\text { pizza crust, crackers }\end{array}$ & 1,3 & Pitochelli 1985 \\
\hline Rallus aquaticus & Food picked up deep in mud & 2 & Caldwell 1951 \\
\hline Sturnus vulgaris & Feather & - & Radford 1979 \\
\hline Tringa hypoleucos & Food probed from the mud & 2 & Simmons 1950 \\
\hline Tringa melanoleuca & Crickets & 2 & Jordheim 1965 \\
\hline Tringa tetanus & Frogs & 2 & Henry et al. 1998 \\
\hline Turdus merula & Leather-jackets & 2 & Watkin 1950 \\
\hline
\end{tabular}

Context (as suggested in the source): $1=$ softening or soaking; $2=$ washing; $3=$ water for nestlings. We excluded reports for birds kept in captivity and cases of drowning of live prey.

instances of bread dunking in nearby rain puddles were observed during various field experiments. Some of the dunked pieces of bread were stolen by conspecifics at the moment of their release in the puddle (kleptoparasitism, reviewed by Brockmann \& Barnard 1979). Enquiries to local ornithologists confirmed that dunking is occasionally observed in wild Carib grackles in different parts of Barbados (M. Frost, personal communication). Quiscalus lugubris is very tame and opportunistic (ffrench 1991) and some aspects of its foraging behaviour and cognition have been well studied in the field in Barbados (Dolman et al. 1996; Lefebvre et al. 1997; Webster \& Lefebvre 2001; Reader et al. 2002). The Carib grackle is thus an ideal species for field and captive studies on dunking.
In this study, we characterized dunking rates in Carib grackles in the wild and examined the effects of food characteristics like dryness and dirtiness, as well as the effects of kleptoparasitism and conspecific density. In addition, we determined the individual propensities for dunking behaviour in the controlled, socially isolated context of captivity, and we compared dunking rates in the same individuals in captivity and in the field. We also assessed individual variation in dunking rate through observations of banded birds in the field. Our aim was to document individual variation and capacities for dunking, examine its proposed costs and benefits, and determine whether dunking is conditionally expressed according to local social conditions. 


\section{GENERAL METHODS}

\section{Study Area}

The study was conducted in and around the grounds of the Bellairs Research Institute of McGill University, St James, Barbados, from January to June 2002. Two of the four field sites (paved terraces: sites A and B), drop traps, and the aviary used for captive experiments were situated on the grounds of the Bellairs Institute. The two other field sites were situated in Folkestone Park (sites C and D), immediately to the south of Bellairs. All four sites were situated at least $50 \mathrm{~m}$ apart from one another.

\section{Experimental Protocol}

Each experiment involved offering either dry dog food pellets or cut pieces of bread. Bread is a regular food source for grackles in urbanized areas of Barbados (Dolman et al. 1996). The dog food pellets $(0.7-\mathrm{cm}$ diameter, $21 \%$ protein; Atlantic Marketing, Barbados) are readily eaten by grackles in captivity and in the wild, although they are apparently difficult to swallow. Ingestion could be facilitated by breaking the hard, dry pellets into pieces, but grackles' repeated pecking at the pellets very rarely resulted in successful breaking of the items.

In field experiments, the food was placed in a clump on the ground at a fixed distance from a consistently present, naturally occurring puddle of water. Position and size (30-cm diameter) of the water puddle was kept constant during experiments by replenishment with tap water. The time of day and site of trials were randomized throughout the observation period.

Other bird species besides grackles took food items during experiments, but never dunked (pellets: Zenaida aurita and Tyrannus dominicensis; bread: $Z$. aurita, T. dominicensis, Loxigilla noctis, Molothrus bonariensis and Coereba flaveola; see Reader et al. 2002). Our analyses addressed only the food items taken by Q. lugubris. Density counts of competitors at a site or a puddle considered only grackles.

\section{Statistical Analysis}

Testing the factors that influence the probability that a food item is dunked or stolen presents two statistical difficulties. First, data are unlikely to be independent, because they may be clustered both by trial and/or individual. For example, observations conducted within trials are likely to be more similar than those recorded between trials, because they are affected by similar conditions (location, weather, number of competitors, etc.). This clustering typically violates the assumption of data independence of standard statistical models. We dealt with this problem by using generalized linear models for autocorrelated data. In experiments 1 and 2, we specified a model with binomial error and logit link (PROC GENMOD in SAS version 8.01, Kuss 2002), in which the response variable in each trial was the proportion of taken items that were dunked. This allowed us to test the influence of type of food on the probability that a food item was dunked, while accounting for the nonindependence of food items from the same trial. When the response variable was binary (item is dunked or not, or stolen or not) we used generalized linear mixed models (\%GLIMMIX macro in SAS version 8.01, Kuss 2002) with binomial error and logit link, including trial (experiment 2 and 3) and/or individual (experiment 3) as random factors. In both GLM approaches, multiple dunking or stealing of any one food item was considered as a single behavioural event. Whenever possible, we double-checked the results using traditional statistical tests (chi-square and sign test). In all cases, the conclusions of our analyses were identical.

The second difficulty is that even when we reduced the possible effects of pseudoreplication by statistically controlling for trial and individual, the link between response and explanatory variables may have been biased by their common correlation with a third variable. To control for the potential effect of some confounding variables, we included date, time, site and density of competitors as covariates in the models.

\section{EXPERIMENT 1: DUNKING RATE IN WILD GRACKLES}

This experiment aimed to systematically document the prevalence of dunking behaviour in the field, and to determine whether food type influenced dunking rate.

\section{Methods}

In each trial, food pieces were presented near a puddle of water, and a single observer noted the response of birds taking food: fly away with the food (fly away), drop it on the dry ground (deposit), or drop it in the puddle (dunk). A trial finished when no more food was available.

We performed 71 trials each involving 12 food items on site A (Seabourne flat, Bellairs). In the first 20 trials, we placed fresh white bread cubes $(1 \times 1 \times 0.5 \mathrm{~cm})$ on two cement columns situated $3 \mathrm{~m}$ and $6 \mathrm{~m}$, respectively, from the water puddle. In a second set of 20 trials, we used pellets of dry dog food. We added two other sets of trials (17 trials with bread, 14 trials with pellets) to control for the possible carryover effects of having the 20 trials with pellets follow the 20 trials with bread.

\section{Results and Discussion}

One to 12 grackles took the food on any one trial. The most frequent response to both bread and pellets was for a grackle to fly away with it to a tree (bread: $93.4 \%$ of responses; pellets: $76.5 \%$ of responses). In comparison, dunking rate was very low: on only 65 of 791 occasions did a grackle fly down from a column with a piece of bread or a pellet in its beak, walk to the puddle and dunk the food in it before eating the food on the spot or flying away 
with it in its beak (bread: $3.2 \%$; pellets: $13.6 \%$ ). In the remaining cases, a grackle flew down from the columns and deposited a food item on a dry part of the terrace (bread: 3.4\%; pellets: 9.9\%); the food was either then simply repositioned in the beak or attempts were made to break the item with the beak. That the observed dunking behaviour represented random dropping of the food is highly unlikely because the puddle covered less than $2 \%$ of the terrace area and was the site of deposition of $56 \%$ of items dropped by grackles. Furthermore, grackles walked directly and rapidly to the puddle with food in their beaks and often deposited an item several times in the water. Pellets were both dunked in water and deposited on a dry part of the terrace more often than bread was (GENMOD, dunking: $\chi_{1}^{2}=12.29, P=0.0005$; GENMOD, depositing: $\left.\chi_{1}^{2}=13.71, P=0.0002\right)$. Intraspecific kleptoparasitic attempts occurred mostly when grackles were depositing items on the ground or when they were releasing food in the puddle in the course of dunking. In the latter cases $(N=29)$, only six attempts $(20.7 \%)$ resulted in successful kleptoparasitism.

This experiment showed that dunking behaviour was rare in the field relative to simply flying away with the food, and that the type of food available could influence dunking rate. In the next experiment, we investigated further the influence of food type on dunking rate to examine possible benefits of the behaviour, and we compared the rate of kleptoparasitism on dunked and nondunked food.

\section{EXPERIMENT 2: THE CONTEXT OF DUNKING: SOFTENING, WASHING AND STEALING}

In this second field experiment, we tested two suggested functions of dunking behaviour (see Table 1) by comparing the rate of dunking of fresh versus dry bread, and of clean bread versus bread rolled in sand. If grackles dunk dry bread more often than fresh bread, this would suggest that they derive a benefit from softening dry and/or hard food. If grackles dunk sandy bread more often than clean bread, a washing benefit to the behaviour would be suggested. We also compared the rate of successful kleptoparasitism on dunked items versus nondunked items; if dunked items tend to be stolen more often than nondunked items, that would suggest that dunking behaviour exposes grackles to an increased risk of theft.

\section{Methods}

We compared dunking rate under two sets of food conditions: fresh versus dry bread (set 1 ), and clean versus sandy bread (set 2). For each of the two sets, a trial consisted of the presentation of one of the two food types near a puddle of water, and ended when all items had been eaten (or after $30 \mathrm{~min}$ ). A single observer noted the duration of each trial, the maximum number of grackles at the site during each trial, the number of food items taken by grackles, and the rate of dunking, stealing bread and stealing dunked bread.
In each set, the two different food types were alternatively offered in pairs of trials (with less than $120 \mathrm{~s}$ between the two trials of a pair), with food type randomized with respect to order, time of day and site throughout the experimental period. We performed 144 trials at three sites (A, B, C). Each trial involved 50 pieces of one type of bread provided in a clump $1 \mathrm{~m}$ from the puddle. Each food piece was prepared from a cube of fresh white bread measuring $1 \times 1 \times 0.5 \mathrm{~cm}$. In the first set, fresh bread cubes were kept in a plastic bag up to the start of the experiment, whereas dry cubes were heated in an oven for $10 \mathrm{~min}$ at $52^{\circ} \mathrm{C}$. In the second set, both clean and sandy bread were moistened before a trial ( $10 \mathrm{ml}$ of tap water per 50 cubes). Clean bread cubes were offered directly after moistening, whereas sandy bread cubes were rolled in $20 \mathrm{ml}$ of sand after moistening.

\section{Results and Discussion}

In the first set, fresh bread was taken at a faster rate than dry bread, as evidenced by the shorter mean duration of the trials involving fresh bread (Mann-Whitney $U$ test: $\left.U=350.0, N_{1}=36, N_{2}=36, P=0.0008\right)$. Dunking rate was higher for dry bread than for fresh bread (6.4\% versus $3.4 \%$, respectively; GENMOD: $\chi_{1}^{2}=8.86, P=0.0029$; Fig. 1). In the second set, clean bread was taken at a faster rate than sandy bread $\left(U=312.5, N_{1}=36, N_{2}=36\right.$, $P=0.0002)$, but dunking rate was not significantly different $\left(2.9 \%\right.$ versus $2.8 \%$; GENMOD: $\chi_{1}^{2}=0.21$, NS; power > 0.8; power estimate (Murphy \& Myors 1998) based on the effect size in the fresh-dry bread comparison and $\alpha=0.05$; Fig. 1). Thus, dunking behaviour was sensitive to food dryness and/or hardness, suggesting that grackles dunked to soften food. By contrast, the coating of food with sand did not appear to alter dunking behaviour, providing no evidence that grackles derived a benefit from washing sandy food.

Kleptoparasitism was significantly more frequent on dunked food (14.6\%) than on nondunked food $(3.8 \%$; GLIMMIX, set $1: F_{1}, 2465=74.72, P<0.0001$; set 2 : $\left.F_{1,2610}=107.78, P<0.0001\right)$, which suggests that dunking exposed grackles to an increased risk of theft. We could not record kleptoparasitic events occurring after

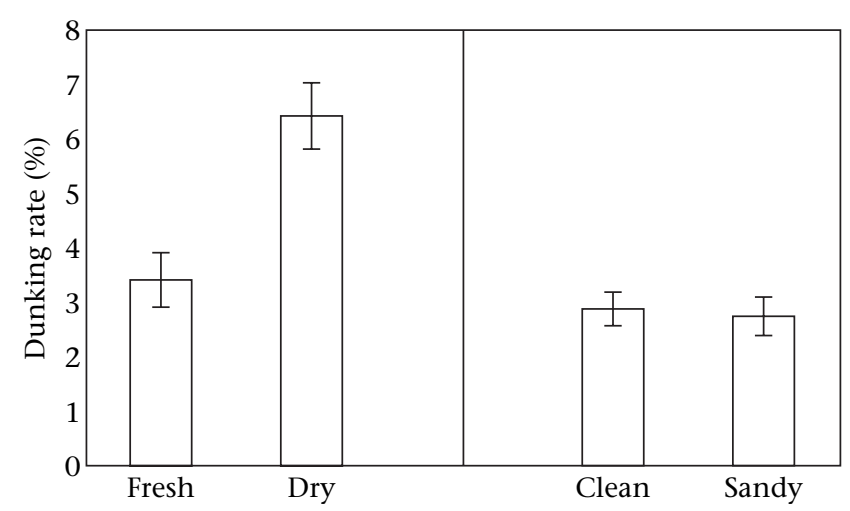

Figure 1. Dunking rate (mean $\pm S E$ percentage of items taken that were dunked) of fresh and dry bread, and of clean and sandy bread. 
grackles had flown away with food outside the limits of our observation site. However, we estimated the probability of this to be very low, because we never saw an aerial pursuit of a bird leaving with bread during these trials.

\section{EXPERIMENT 3: OBSERVATIONS IN THE FIELD AND IN CAPTIVITY}

In this set of experiments, we observed dunking behaviour in captive individuals, then released these individuals and made systematic field observations on them and on other free-ranging, individually marked grackles. We presented both captive and free-ranging grackles with hard, dry food pellets near a water source to determine individuals' propensities to dunk (1) in isolation, where no kleptoparasitism is possible and no alternative food is offered, and (2) in the field, where other feeding and behavioural options are available.

Thirty-six grackles were caught in baited drop traps, banded, and housed individually in aviaries for 10 days with ad libitum access to water. All birds ate some of the food pellets provided each day during two daily, 20-min sessions. Thirty-one (86\%) of these individuals were observed dunking. All birds were then released near their site of capture. We conducted field observations on the marked grackles at four sites in May and June 2002. In addition to the 36 birds studied in captivity, we had banded 124 wild grackles using unique combinations of coloured metal leg rings between February 2001 and May 2002. There was no significant relationship between individual dunking rates in captivity and in subsequent field observations (Pearson's regression: $F_{1,15}=0.135$, NS). Because the frequency distribution of dunking rate in individuals that had been in captivity did not differ from that of grackles that had not been in captivity (Kolmogorov-Smirnoff test: $D=0.355, N=74, \mathrm{NS}$ ), and because released grackles did not dunk more in the field than the ones that had not been in captivity previously (GLIMMIX: $\mathrm{F}_{1,2142}=0.336$, NS), we pooled all individuals for analysis.

Seventy-four recognizable individuals were observed more than three times in the field. Most of these birds showed either no or very low rates of dunking, but approximately a quarter (18/74) showed rates varying between $25 \%$ and $83.3 \%$, with an average dunking rate of $13 \%$ (Fig. 2). The observed frequency distribution of dunking was tested against two theoretical distributions: one in which all birds dunked at the average 13\% rate (no specialization) and one at which 13\% of the birds did all the dunking (complete specialization). Tests of goodness of fit revealed that neither of the theoretical distributions accounted for the observed distribution in Fig. 2 (Kolmogorov-Smirnoff test: $D=0.730, N=74, \quad P<0.0001$; $D=0.473, N=74, P<0.0001)$. Nevertheless, mixedmodel analysis revealed consistent individual differences in dunking propensity, with the variation in dunking rate between individuals being greater than the variation within individuals (GLIMMIX: $Z=3.31, P=0.0005$ ). We found no evidence that these differences were associated with sex (GLIMMIX: $F_{1}, 2142=1.88$, NS) or age (GLIMMIX: $\left.F_{1,2142}=0.69, \mathrm{NS}\right)$. We also found consistent individual differences in rate of stealing (GLIMMIX: $Z=2.92, \quad P=0.0018$ ) as well as being stolen from (GLIMMIX: $Z=2.11, P=0.0173$ ).

Of the 74 individuals observed in the field, 45 were observed dunking, 28 were observed stealing, and 29 were victims of kleptoparasitism. We could not analyse individual concordance between dunking, stealing and being stolen from with mixed models, because the prevalence of the three behaviours was low compared to flying away with pellets. However, as is clear from Fig. 3a-c, some birds showed all three behaviours, whereas others showed only one or none.

In the field, dunking rate showed a strong negative association with the density of grackles at the puddle

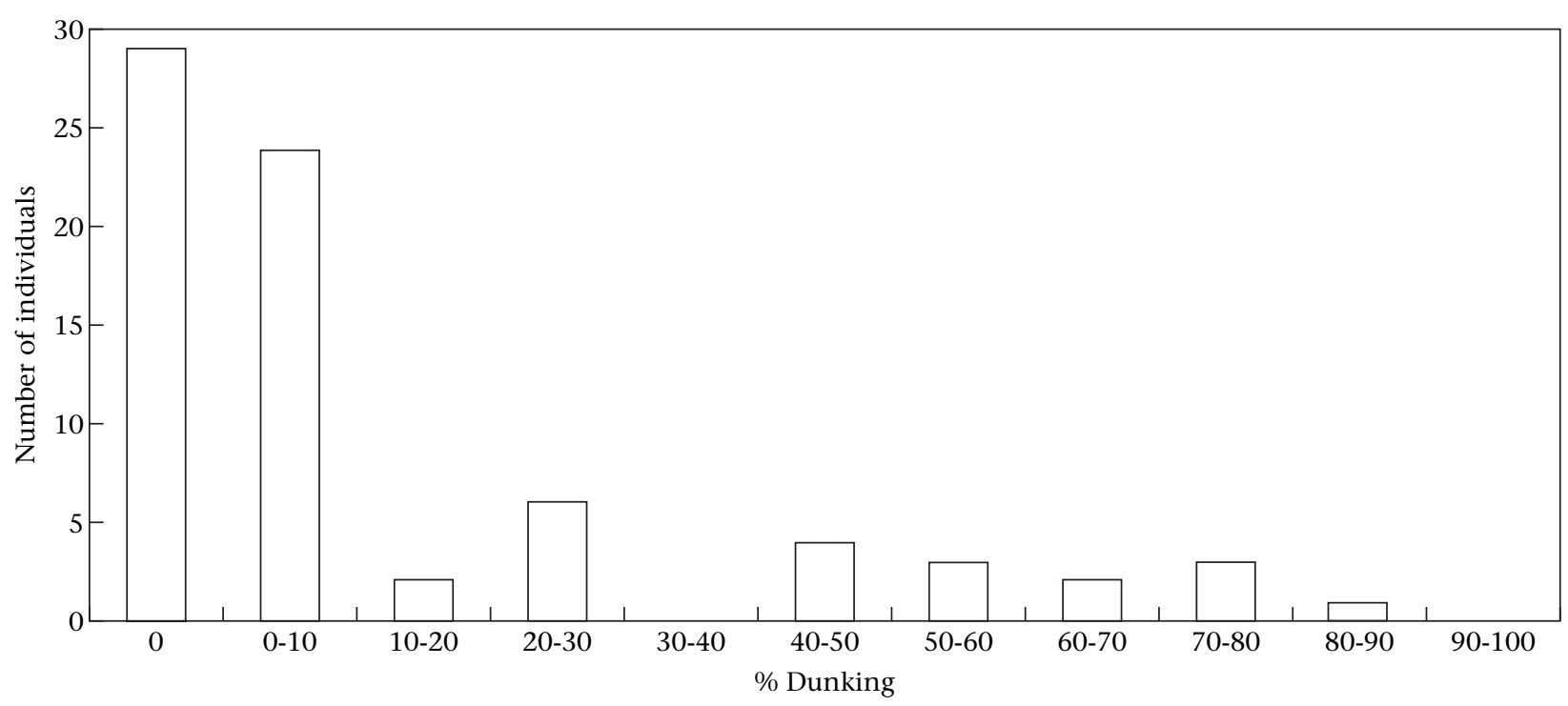

Figure 2. Observed frequency distribution of dunking (percentage of behavioural events that were dunking events) in the field. 

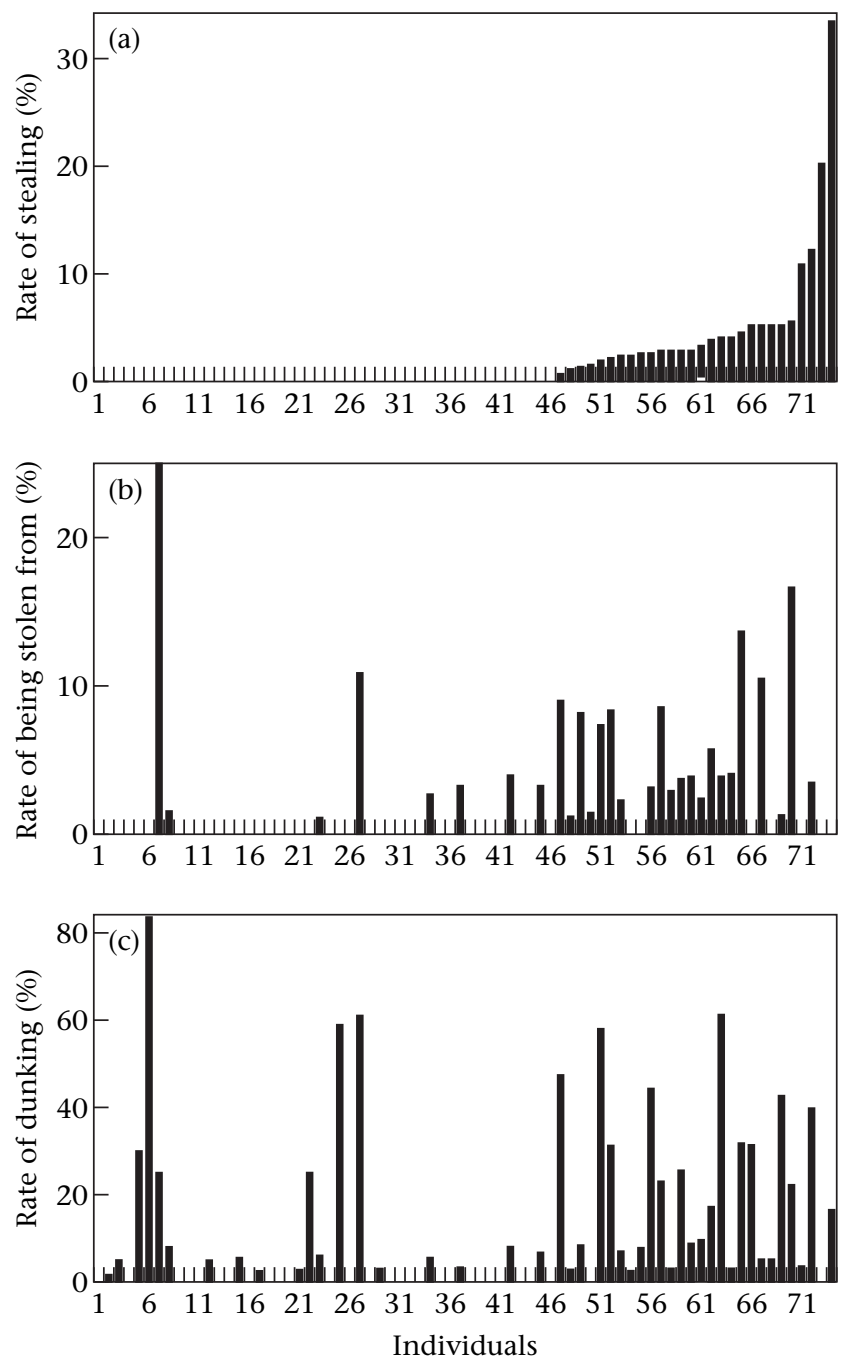

Figure 3. Individual rates of (a) stealing, (b) being stolen from and (c) dunking, expressed as percentages of the total number of behavioural events. Individuals occupy the same position on the $X$ axis of all three graphs, and are sorted by increasing rate of stealing (a).

(GLIMMIX: $\left.F_{1,2142}=18.61, P<0.0001\right)$. To explore further the effect of conspecific density on dunking and kleptoparasitic behaviours, we ran additional trials in which the food was placed between two puddles of water spaced $4 \mathrm{~m}$ apart. We noted for each food item dunked the number of grackles present at both puddles and whether or not the food item was stolen. Grackles dunked at the lowdensity puddle in $77 \%$ of the 288 dunking observations in which there was a difference in conspecific density at the two puddles. In the few cases where grackles dunked at the high-density puddle, they were six times more likely to be kleptoparasitized than birds using the low-density puddle (GLIMMIX: $F_{1,490}=19.54, P<0.0001$ ).

\section{GENERAL DISCUSSION}

Our experiments suggest that most, if not all, Carib grackles in Barbados are capable of dunking, but that the behaviour is conditionally expressed according to environmental and social conditions. Field experiments 1 and 2 showed that the frequency of dunking was higher with hard, dry food than with soft, moist food. Thus, dunking appears to be a food-processing technique that eases ingestion of dry and/or hard food through softening. However, we cannot exclude the alternative possibilities that (1) dry food promotes thirst, causing grackles to approach water at increased rates, and thereby promotes dunking as a side-effect of their drinking behaviour or proximity to water (Heinrich 1999), or that (2) dry food acts as a better 'sponge' to aid water ingestion for the individual itself, or for its nestlings (Koenig 1985). Most grackles were observed eating dunked food on the spot, but because the breeding status of birds departing with dunked food was not known, we cannot reject the possibility that dunked food was given to nestlings; indeed, one free-ranging female was observed dunking bread and feeding it to a nearby juvenile in February 2002. If the food is used as a sponge during dunking, then the behaviour would be an example of tool use (see Van Lawick-Goodall 1970; Beck 1980; McFarland 1982; Lefebvre et al. 2002). Despite the fact that almost all the sand covering the bread in experiment 2 could be quickly removed by dunking, grackles did not dunk sandy bread more often than clean bread. Thus, washing of sandcovered food does not appear to be an important function of dunking in Q. lugubris. Other food characteristics may however elicit the behaviour. For example, captive grackles also dunk sticky maraschino cherries (S. M. Reader, personal observation).

Social context also seemed to influence the frequency of the behaviour. Dunking rate was negatively associated with conspecific density at the puddle (experiment 3). Higher grackle densities were also associated with an increased risk of kleptoparasitism when birds could dunk at one of two puddles, and birds generally dunked at the puddle with lower conspecific densities. Costs associated with the potential theft of food items (wasted time and energy, lost opportunities for energy and nutrients, risk of injuries, etc.) may have influenced grackles' use of dunking behaviour, as dunking seemed to expose them to an increased risk of kleptoparasitism (experiment 2). A similar observation has been made by Visalberghi \& Fragaszy (1990) on one Macaca fascicularis that was kleptoparasitized by conspecifics when dunking sandy fruits in captivity; the female dunked more often when conspecifics were away from the water source.

Our results indicate that the low frequency of an apparently complex foraging technique need not indicate that only a few individuals are capable of its performance. To address this issue, individuals need to be tested under conditions favourable to the expression of the behaviour (e.g. Drea \& Wallen 1999), but still have the option of not performing it. In our study, aviary conditions were favourable to dunking (i.e. hard, dry food near water, with no risk of kleptoparasitism), but grackles could still feed by swallowing the pellets whole. If a majority of individuals show the technique in favourable conditions, as grackles did here, the rarity of the behaviour in normal field situations may result from variation in the costs and 
benefits experienced by individuals in different situations, rather than an inability to perform the technique. Tebbich et al. (2002) have shown that woodpecker finches frequently use twig tools in the wild in arid habitats, but very rarely do so in humid ones. In captive conditions where tool use was encouraged by hiding food in slits, however, wild-caught juvenile finches developed tool use, whether they were from arid habitats or more humid ones (Tebbich et al. 2001). Many behaviour patterns will be sensitive to prevailing conditions, the efficiency of alternative techniques, and the (possibly frequency-dependent) balance of costs and benefits for a particular individual. The rare performance of a behaviour pattern need not suggest that performers possess unusual capacities compared to their conspecifics.

Our results do not rule out the possibility that dunking was produced de novo by each individual in captivity. However, the finding that a majority of our Carib grackles dunked at least once in the field (33 out of 57 wild grackles that had not been in captivity previously), added to the fact that five out of the six Quiscalus species have now been reported to dunk (Q. quiscula, Q. mexicanus and Q. major, see Table 1; Q. lugubris, this study; Q. niger, A. S. Griffin, personal communication; no record for Q. nicaraguensis), support Jackson's (1985) suggestion of a possible generalized propensity to dunk in this genus.

\section{Acknowledgments}

We are grateful to Éric Trottier and Martin Frost for their help in the field, and to Luc-Alain Giraldeau for comments on a previous version of the paper. Funding for this work was provided by a National Sciences and Engineering Research Council (NSERC) grant to L.L. and an NSERC postgraduate scholarship to J.M.F. The study was conducted under McGill University Animal Use Protocol number 4519 .

\section{References}

Banks, S. 1982. Grey heron dunking and swallowing large rat. British Birds, 75, 181.

Beck, B. B. 1980. Animal Tool Behavior: the Use and Manufacture of Tools by Animals. New York: Garland.

Bent, A. C. 1958. Life histories of North American blackbirds, orioles, tanagers, and allies. U.S. National Museum Bulletin, 211, 395-421.

Bowey, K. 1997. Grey heron catching common starling in flight. British Birds, 90, 112-113.

Brampton, A. H. 1994. Carrion crow dunking nuts. British Birds, 87, 478

Brockmann, H. J. \& Barnard, C. J. 1979. Kleptoparasitism in birds. Animal Behaviour, 27, 487-514.

Caldwell, J. A. 1951. Food-washing in the water-rail. British Birds, 44, 418.

del Hoyo, J., Elliott, A., Sargatal, J. (Eds) 1996. Handbook of the Birds of the World, Vol. 3. Barcelona: Lynx Edicions.

Dolman, C. S., Templeton, J. \& Lefebvre, L. 1996. Mode of foraging competition is related to tutor preference in Zenaida aurita. Journal of Comparative Psychology, 110, 45-54.

Drea, C. M. \& Wallen, K. 1999. Low-status monkeys "play dumb" when learning in mixed social groups. Proceedings of the National Academy of Sciences, U.S.A., 96, 12965-12969.
Edmonds, J. 1991. Burnt offerings. Bird Observer, 715, 10.

ffrench, R. 1991. A Guide to the Birds of Trinidad and Tobago. Ithaca, New York: Cornell University Press.

Goodwin, D. 1986. Crows of the World. 2nd edn. London: British Museum.

Heinrich, B. 1999. Mind of the Raven. New York: Harper Collins.

Henry, P.-Y., Bénéat, Y. \& Maire, P. 1998. Redshank Tringa totanus feeding on young edible frogs Rana kl. esculenta. Nos Oiseaux, 45, 57-58.

Higuchi, H. 1988. Individual differences in bait-fishing by the greenbacked heron associated with territory quality. Ibis, 130, 39-44.

Jackson, J. 1985. The dunking habit of common grackles. American Birds, 39, 261-262.

Johnson, I. W. 1976. Washing of food by spotless crake. Notornis, 23, 357.

Jones, C. G. 1979. Birds dunking food. British Birds, 72, 189-190.

Jordheim, S. O. 1965. Unusual feeding behaviour of yellowlegs. Blue Jay, 23, 25.

Koenig, W. D. 1985. Dunking of prey by Brewer's blackbirds: a novel source of water for nestlings. Condor, 87, 444-445.

Kuss, O. 2002. How to use SAS for logistic regression with correlated data. Proceedings of the Annual SAS Users Group International Conference, 27, 1-5.

Lefebvre, L., Templeton, J., Brown, K. \& Koelle, M. 1997. Carib grackles imitate conspecific and Zenaida dove tutors. Behaviour, 134, 1003-1017.

Lefebvre, L., Nicolakakis, N. \& Boire, D. 2002. Tools and brains in birds. Behaviour, 139, 939-973.

Lefebvre, L., Reader, S. M. \& Sol, D. 2004. Brains, innovations and evolution in birds and primates. Brain, Behavior and Evolution, 63, 233-246.

Luchtemeyer, E. A. 1969. Unusual behavior of robin, Turdus migratorius, and red-winged blackbirds, Agelaius phoenicus. Florida Naturalist, 42, 135.

McFarland, D. 1982. The Oxford Companion to Animal Behaviour. Oxford: Oxford University Press.

Mackay, S. 1997. Ravens again. Bird Observer, 776, 10.

McMillan, M. 1992. How to feed muppets-soak the bones! Bird Observer, 12, 726.

Murphy, K. R. \& Myors, B. 1998. Statistical Power Analysis: a Simple and a General Model for Traditional and Modern Hypothesis Tests. Mahwah, New Jersey: L. Erlbaum.

Nicklas, B. 1974. Bird behavior. Chat, 38, 88.

Nimmo, C. E., Jr. 1970. Birds and water. Raven, 41, 59-63.

Otnes, G. 1977. Unusual feeding behavior of a great blue heron. Loon, 49, 233.

Pitochelli, J. 1985. Apparent insight learning by some common grackles breeding in Central Park, New York. Kingbird, Winter, 32-33.

Pulich, W. M. 1969. Unusual behavior of three species of birds. Wilson Bulletin, 81, 472.

Purser, G. L. 1959. House sparrows soaking hard bread to soften it. British Birds, 52, 199-200.

Radford, A. P. 1979. Starling eating feather. British Birds, 72, 188.

Rand, A. L. 1967. A common grackle learning to soak bread. Wilson Bulletin, 79, 455-456.

Reader, S. M. \& Laland, K. N. 2002. Social intelligence, innovation, and enhanced brain size in primates. Proceedings of the National Academy of Sciences, U.S.A., 99, 4436-4441.

Reader, S. M. \& Laland, K. N. (Eds) 2003. Animal Innovation. Oxford: Oxford University Press.

Reader, S. M., Morand-Ferron, J., Côté, I. \& Lefebvre, L. 2002. Unusual feeding behaviors in five species of Barbadian birds. El Pitirre, 15, 117-123. 
Reid, D. \& Reid, S. 1996. Corvus coronoides - not just a pretty face. Bird Observer, 766, 7.

Schardien, B. J. \& Jackson, J. A. 1982. Killdeers feeding on frogs. Wilson Bulletin, 94, 85-87.

Seibt, U. \& Wickler, W. 1978. Marabou storks wash dung beetles. Zeitschrift für Tierpsychologie, 46, 324-327.

Simmons, K. E. L. 1950. Food-washing by common sandpiper. British Birds, 43, 229-230.

Slee, J. E. 1992. Little raven eating toast. Bird Observer, 723, 12.

Stokes, D. \& Stokes, L. 1985. Bird song. Part II. Bird Watcher's Digest, 7, 54-59.

Tebbich, S., Taborsky, M., Fessl, B. \& Blomqvist, D. 2001. Do woodpecker finches acquire tool-use by social learning? Proceedings of the Royal Society of London, Series B, 268, 2189-2193.

Tebbich, S., Taborsky, M., Fessl, B. \& Dvorak, M. 2002. The ecology of tool-use in the woodpecker finch. Ecology Letters, 5, 656-664.
Vader, W. 1979. Cleptoparasitism on bar-tailed godwits by common gulls. Fauna, 32, 62-65.

Van Lawick-Goodall, J. 1970. Tool-using in primates and other vertebrates. Advances in the Study of Behaviour, 3, 195-249.

Visalberghi, E. \& Fragaszy, D. M. 1990. Food-washing behaviour in tufted capuchin monkeys, Cebus apella, and crabeating macaques, Macaca fascicularis. Animal Behaviour, 40, 829-836.

Watkin, R. 1950. Food-washing by blackbird. British Birds, 43, 156.

Webster, S. J. \& Lefebvre, L. 2001. Problem solving and neophobia in a columbiform-passeriform assemblage in Barbados. Animal Behaviour, 62, 23-32.

Wible, M. W. 1975. Food washing by grackles. Wilson Bulletin, 87, 282-283.

Zach, R. 1979. Shell dropping: decision-making and optimal foraging in Northwestern crows. Behaviour, 68, 106-177. 